\title{
Gender-Specific Association of the Brain-Derived Neurotrophic Factor Gene with Attention-Deficit/Hyperactivity Disorder
}

\author{
Soo-Churl Cho', Hyo-Won Kim ${ }^{1} \bowtie$, Boong-Nyun Kim¹, Jae-Won Kim¹, Min-Sup Shin ${ }^{1}$, Seockhoon Chung², \\ Dae-Yeon $\mathrm{Cho}^{3}$, Sun-Woo Jung ${ }^{1}$, Hee Jeong $\mathrm{Yoo}^{4}$, In-Won Chung ${ }^{5}$, Un-Sun Chung ${ }^{6}$ and Jung-Woo Son ${ }^{7}$ \\ ${ }^{1}$ Department of Child and Adolescent Psychiatry, Seoul National University College of Medicine, Seoul, Korea \\ ${ }^{2}$ Department of Psychiatry, University of Ulsan College of Medicine, Asan Medical Center, Seoul, Korea \\ ${ }^{3}$ LabGenomics Clinical Research Institute, Seoul, Korea \\ ${ }^{4}$ Department of Psychiatry, Seoul National University Bundang Hospital, Seongnam, Korea \\ ${ }^{5}$ Department of Neuropsychiatry, Dongguk University College of Medicine, Goyang, Korea \\ ${ }^{6}$ Department of Psychiatry, Kyungpook National University College of Medicine, Daegu, Korea \\ ${ }^{7}$ Department of Psychiatry, Chungbuk National University College of Medicine, Cheongju, Korea
}

Objective Attention-deficit/hyperactivity disorder (ADHD) is a complex neurodevelopmental disorder with a strong genetic component. Brain-derived neurotrophic factor (BDNF), which participates in the differentiation and survival of dopaminergic and noradrenergic neurons, could play a role in ADHD development. We aimed to explore the relationships between ADHD and BDNF gene polymorphism.

Methods We conducted a case-control analysis of 202 ADHD subjects and 159 controls, performed a transmission disequilibrium test on 151 trios, and compared the results of a continuous performance test (CPT) according to the genotype of the three single nucleotide polymorphisms (rs11030101, rs6265, rs16917204) in the BDNF gene.

Results In the case-control analysis, the AA genotype of the BDNF rs11030101 polymorphism was significantly associated with ADHD only in girls $(\mathrm{p}=0.024$, odds ratio=3.00). The T-G-G haplotype was significantly less frequent $(\mathrm{p}=0.005)$ and $\mathrm{A}-\mathrm{G}-\mathrm{G}$ was more frequent $(\mathrm{p}=0.048$ ) in girls with $\mathrm{ADHD}$ than in control girls (global $\mathrm{p}=0.027$ ). A multivariate analysis of variance for commission errors on the $\mathrm{CPT}$ showed a significant main effect for the rs11030101 genotype ( $\mathrm{p}=0.026)$ and an interaction effect of the rs11030101 genotype and gender $(\mathrm{p}=0.032)$ in $\mathrm{ADHD}$ probands.

Conclusion These results provide preliminary evidence for a gender-specific association between BDNF and ADHD in the Korean population.

Psychiatry Investig 2010;7:285-290

Key Words Association studies, Attention-deficit/hyperactivity disorder, Brain-derived neurotrophic factor, Continuous performance test, Single nucleotide polymorphism.

\section{INTRODUCTION}

Attention-deficit/hyperactivity disorder (ADHD), which affects about $5 \%$ of school-aged children worldwide, ${ }^{1}$ is a neurodevelopmental disorder characterized by inattention, hyperac-

Received: May 10, 2010 Revised: August 31, 2010

Accepted: September 15, 2010 Available online: November 23, 2010

$\triangle$ Correspondence: Hyo-Won Kim, MD, PhD

Department of Child and Adolescent Psychiatry, Seoul National University College of Medicine, 101 Daehak-ro, Jongno-gu, Seoul 110-799, Korea

Tel: +82-2-3010-3414, Fax: +82-2-485-8381, E-mail: shingubi@gmail.com

(c) This is an Open Access article distributed under the terms of the Creative Commons Attribution Non-Commercial License (http://creativecommons.org/licenses/by$\mathrm{nc} / 3.0$ ) which permits unrestricted non-commercial use, distribution, and reproduction in any medium, provided the original work is properly cited. tivity, and impulsivity. ADHD causes social, academic, and behavioral problems and persists into adulthood in $30-50 \%$ of cases. ${ }^{1}$ Familial and genetic studies strongly support a role for a genetic component in ADHD pathogenesis, and the estimated heritability is approximately $80 \%{ }^{2}$

The catecholamine systems have been implicated in the pathophysiology of ADHD, and genes modulating dopamine and norepinephrine system have been studied extensively. ${ }^{2}$ Nevertheless, evidence from neurobiological and pharmacological research supports the role of neurotrophic factors in ADHD pathogenesis. Given that ADHD is a neurodevelopmental disorder, neurotrophic factors supporting neuronal survival, proliferation, and differentiation, as well as survival and synaptic 
plasticity in the central nervous system, ${ }^{3}$ might be involved in ADHD susceptibility. Among neurotrophic factors, brain-derived neurotrophic factor (BDNF), which is critical for the survival and differentiation of midbrain dopaminergic neurons ${ }^{4}$ and the phenotypic differentiation of locus ceruleus noradrenergic neurons, ${ }^{5}$ has been a focus.

BDNF messenger RNA is expressed in the mesolimbic dopaminergic system, the prefrontal cortex, the limbic system, and the cerebellum, ${ }^{3}$ which have been implicated in ADHD pathogenesis. BDNF gene expression is reduced in the frontal cortex of dopamine transporter knockout mice, which is considered as an animal model for ADHD. ${ }^{6}$ BDNF conditional knockout mice exhibit increased locomotor hyperactivity, which mimics the fundamental behavioral characteristics of ADHD. ${ }^{7}$ Moreover, BDNF mediates psychostimulant-induced neuroadaptations and locomotor activity through the dopaminergic, serotoninergic, and noradrenergic neurotransmitter systems. ${ }^{8}$ A recent study reported a positive correlation between plasma BDNF levels and severity of omission errors on the continuous performance test (CPT) in patients with ADHD. ${ }^{9}$

Previous studies have shown inconsistent results regarding the relationship between the BDNF gene and ADHD. Casecontrol studies ${ }^{8,10,11}$ have shown negative results, but in one study, ${ }^{11}$ a haplotype containing the rs6265 G allele increased significantly in children with ADHD. Family-based association analyses are also not in agreement. ${ }^{10-13}$ In quantitative trait analysis, there is some evidence of association of parent-rated symptoms and cognitive functions. ${ }^{14}$ However, no study has investigated the association between the BDNF gene and the results of the CPT.

Thus, we aimed to evaluate the relationships between ADHD and BDNF gene polymorphisms by conducting case-control and family-based association studies of the BDNF gene and by comparing the results of the CPT based on the genotype of the $\mathrm{BDNF}$ gene in a Korean sample.

\section{METHODS}

The subjects with ADHD and their parents were recruited through the Department of Child and Adolescent Psychiatry at three university-affiliated hospitals in Korea (Seoul National, Kyungpook National, and Chungbuk National Hospitals). All subjects with ADHD met the following inclusion criteria: 1) DSM-IV diagnosis of ADHD; 2) above the $90^{\text {th }}$ percentile in the ADHD Rating Scale-IV (ARS); $;^{15}$ 3) T-scores greater than 60 on the attention problems profile of the Child Behavior Checklist (CBCL); ${ }^{16}$ and 4) intelligence quotient (IQ) higher than 71 on the Korean Educational Developmental Institute's Wechsler Intelligence Scale for Children (KEDI-WISC). ${ }^{17}$

The control group was recruited from nine elementary schools in Seoul, Incheon, Seongnam, Ulan, and Yeoncheon, Korea. The children selected for the control group 1) did not meet the criteria for the DSM-IV diagnosis of ADHD; 2) scored below the $90^{\text {th }}$ percentile on the ARS; 3) had T-scores of less than 60 on the attention problems profile of the CBCL; and 4) had IQ scores higher than 71 on the KEDI-WISC.

Subjects were excluded from the study if they had one or more of the following: 1) past and/or current history of neurological disorder, including seizure disorder or brain damage; and 2) presence of comorbid psychosis, Tourette's, bipolar, communication, learning, or pervasive developmental disorder.

We obtained written informed consent from the parents of all children who participated in the study and approval from the institutional review boards at each institution where the study was performed.

The diagnoses of ADHD and comorbid disorders of the ADHD subjects were determined using the Korean version of the Schedule for Affective Disorders and Schizophrenia for SchoolAged Children-Present and Lifetime Version (K-SADS-PL-K). ${ }^{18}$ The children in the control group did not meet the criteria for $\mathrm{ADHD}$ according to the Korean version of the Diagnostic Interview Schedule for Children Version-IV (DISC-IV). ${ }^{19,20}$

A computerized CPT was used to measure cognitive functions. ${ }^{21} \mathrm{~A}$ visual stimulus was presented every $2 \mathrm{sec}$ for $100 \mathrm{~ms}$, and subjects were asked to respond to a square containing a triangle (target), but not to a square containing a circle or a square (nontarget). The target stimulus was presented in $22.5 \%$ of the trials during the first half and in $77.5 \%$ of the trials during the second half of the CPT. The four major variables recorded were 1) omission errors, 2) commission errors, 3) response time, and 4) the standard deviations of the response time for correct responses to the target (response time variability).

Genomic DNA was extracted from blood (stored frozen) using the G-DEX ${ }^{\mathrm{TM}}$ II Genomic DNA Extraction Kit (Intron, Seongnam, Korea). The detection of a single nucleotide polymorphism (SNP) was based on analysis of primer extension products generated from previously amplified genomic DNA using a chipbased MALDI-TOF mass spectrometry platform (Sequenom, Inc., San Diego, CA, USA). All primers in the PCR and hME reactions were designed using Assay Designer 3.1 (Sequenom) (5'ACGTTGGATGGCTTGACATCATTGGCTGAC and 5'-ACGTTGGATGTTTTCTTCATTGGGCCGAAC for the rs6265; 5'ACGTTGGATGACCCACCAGAAAGCTCAATC and 5'ACGTTGGATGTCCTGTTTCTAATCACAGGG for the rs16917204; 5'-ACGTTGGATGCCTGTAAAACAGGATGGCTC and 5'-ACGTTGGATGATGGCTCCAGGAAAGAG TTC for the rs11030101).

We tested the family-based and case-control associations for each individual polymorphism and haplotype using the standard transmission disequilibrium test (TDT) method in Hap- 
loview (http://www.broad.mit.edu/mpg/haploview/) or SNPAlyzer software ver 7.0 (Dynacom, Chiba, Japan). Multivariate analysis of variance (MANOVA) was computed to examine the effect of BDNF genotype and gender on the result of the CPT. SPSS (ver. 15.0) was used for the analysis.

\section{RESULTS}

This study included 202 subjects with ADHD (9.0 \pm 2.5 years) and 159 normal children ( $9.0 \pm 2.7$ years) for the case-control analysis. Table 1 illustrates demographic and clinical characteristics of ADHD and control subjects. The mean ages of the two groups were not significantly different $(\mathrm{p}=0.924)$. The gender distribution of the two groups did differ significantly; 174 ADHD subjects and 111 normal controls were boys $\left(\chi^{2}=14.67\right.$, $\mathrm{p}<0.001)$. Thus, the case-control and family-based analyses of boys and girls were conducted separately. The mean age, IQ, inattention, hyperactivity and total scores of ARS, and ADHD subtype were not significantly different between genders $(\mathrm{p}=$ $0.797,0.714,0.531,0.981,0.755,0.088$, respectively). Comorbidity with oppositional defiant, conduct, mood, anxiety disorder, and enuresis were not different between genders $(\mathrm{p}=0.773,1,1$, $0.087,0.652$, respectively). All participants were ethnically Korean. The family-based analysis included 151 trios consisting of an affected subject and his or her biological father and mother.

The genotype distribution of the three SNPs did not deviate from expectations based on the Hardy-Weinberg equilibrium ( $p>0.05$ ). In a case-control analysis, the A allele and AA genotype of the rs11030101 were significantly higher in girls with
$\mathrm{ADHD}$ than in control girls. The odds ratios of the A allele and AA genotype were 2.64 [95\% confidence interval $(\mathrm{CI})=1.19-5.88$ ] and 3.00 (95\% CI=1.14-7.91), respectively. We found no significant differences between the $\mathrm{ADHD}$ and control groups in the genotype or allele frequencies for boys or in other polymorphisms (Table 2).

The results of the linkage disequilibrium analysis revealed that the three BDNF SNPs were in strong disequilibrium (rs11030101-rs16917204, $\mathrm{r}^{2}=0.328$; rs16917204-rs6265, $\mathrm{r}^{2}=0.404$; rs11030101-rs6265, $\mathrm{r}^{2}=0.864$ ). In the haplotype analysis (Table 3 ), the T-G-G haplotype was significantly less frequent ( $p=0.005)$ and A-G-G was more frequent $(\mathrm{p}=0.048)$ in girls with ADHD than in control girls ( $\mathrm{p}$-value for global test=0.027). We found no significant differences in haplotype frequency in the $\mathrm{ADHD}$ and control boys.

The TDT analysis showed a trend toward the preferential transmission of the A allele of the BDNF rs6265 polymorphism $(\mathrm{p}=0.059)$ in girls (Table 4). No preferential transmission was found for boys or in other polymorphisms.

A total of $173 \mathrm{ADHD}$ subjects without missing data were included in the MANOVA to examine the effect of BDNF genotype and gender on the CPT results.

We found no significant differences between excluded and included subjects with regard to demographic and clinical characteristics. The MANOVA for commission errors on the CPT showed a significant main effect of the rs11030101 genotype $\left(\mathrm{F}_{1}=5.028, \mathrm{p}=0.026\right)$ and an interaction effect of the rs11030101 genotype and gender $\left(\mathrm{F}_{1}=4.679, \mathrm{p}=0.032\right)$ in $\mathrm{ADHD}$ probands (Table 5).

Table 1. Demographic and clinical characteristics of the subjects with ADHD and controls

\begin{tabular}{|c|c|c|c|c|}
\hline & $\operatorname{ADHD}(\mathrm{N}=202)$ & Control $(\mathrm{N}=159)$ & t or $\chi^{2}$ & p-value \\
\hline Age in yr, mean (SD) & $9.0(2.5)$ & $9.0(0.7)$ & -0.06 & 0.924 \\
\hline Gender, boys, N (\%) & $174(86.1 \%)$ & $111(69.8 \%)$ & 14.67 & $<0.001$ \\
\hline IQ, mean (SD) & $106.2(14.8)$ & $114.8(15.3)$ & 5.33 & $<0.001$ \\
\hline \multicolumn{5}{|l|}{$\mathrm{ADHD}$ rating scale } \\
\hline Inattention score & $14.3(6.2)$ & $4.9(4.8)$ & 14.66 & $<0.001$ \\
\hline Hyperactivity score & $10.5(6.0)$ & $3.2(4.1)$ & 12.36 & $<0.001$ \\
\hline Total score & $24.8(10.5)$ & $8.1(8.3)$ & 15.21 & $<0.001$ \\
\hline \multicolumn{5}{|c|}{ Child behavior checklist (CBCL) } \\
\hline Withdrawn & $58.3(8.2)$ & $53.0(8.1)$ & 5.63 & $<0.001$ \\
\hline Somatic complaints & $53.3(5.0)$ & $51.8(3.5)$ & 2.91 & 0.004 \\
\hline Anxious/Depressed & $56.9(7.5)$ & $51.7(5.0)$ & 7.01 & $<0.001$ \\
\hline Social problems & $61.2(9.4)$ & $51.3(4.2)$ & 11.86 & $<0.001$ \\
\hline Thought problems & $57.3(7.7)$ & $51.6(5.1)$ & 7.56 & $<0.001$ \\
\hline Attention Problems & $61.4(8.0)$ & $51.4(3.7)$ & 13.91 & $<0.001$ \\
\hline Delinquent behaviors & $55.4(6.4)$ & $50.9(4.7)$ & 6.95 & $<0.001$ \\
\hline Aggressive behaviors & $60.0(8.9)$ & $51.0(4.3)$ & 11.24 & $<0.001$ \\
\hline
\end{tabular}

ADHD: attention-deficit/hyperactivity disorder, BDNF: brain-derived neurotrophic factor, IQ: intelligence quotient 
Table 2. Comparison of the allele frequencies of BDNF polymorphisms between ADHD probands and controls

\begin{tabular}{|c|c|c|c|c|c|c|c|c|c|c|c|c|c|c|c|}
\hline \multirow{2}{*}{ Marker } & & \multicolumn{3}{|c|}{ Cases, N (\%) } & \multicolumn{3}{|c|}{ Controls, N (\%) } & \multirow{2}{*}{$\begin{array}{c}\chi^{2} \\
(2 \mathrm{df})\end{array}$} & \multirow{2}{*}{$\mathrm{p}$} & \multicolumn{2}{|c|}{ Cases, N (\%) } & \multicolumn{2}{|c|}{ Controls, N (\%) } & \multirow{2}{*}{$\begin{array}{c}\chi^{2} \\
(1 \mathrm{df})\end{array}$} & \multirow{2}{*}{$\mathrm{p}$} \\
\hline & & 11 & 12 & 22 & 11 & 12 & 22 & & & 1 & 2 & 1 & 2 & & \\
\hline \multirow[t]{4}{*}{ rs11030101 } & Boys & 80 & 76 & 18 & 54 & 43 & 14 & 0.810 & 0.667 & 236 & 112 & 151 & 71 & 0 & 0.960 \\
\hline & & $(46.0)$ & $(43.7)$ & $(10.3)$ & $(48.6)$ & $(38.7)$ & $(12.6)$ & & & $(67.8)$ & $(32.2)$ & $(68.0)$ & $(32.0)$ & & \\
\hline & Girls & 18 & 10 & 0 & 18 & 25 & 5 & & $0.035^{*}$ & 46 & 10 & 61 & 35 & 5.87 & 0.015 \\
\hline & & $(64.3)$ & $(35.7)$ & (0) & $(37.5)$ & $(52.1)$ & $(10.4)$ & & & $(82.1)$ & $(17.9)$ & $(63.5)$ & $(36.5)$ & & \\
\hline \multirow[t]{4}{*}{ rs6265 } & Boys & 56 & 84 & 34 & 34 & 51 & 26 & 0.615 & 0.735 & 196 & 152 & 119 & 103 & 0.405 & 0.525 \\
\hline & & $(32.2)$ & $(48.3)$ & (19.5) & $(30.6)$ & $(45.9)$ & $(23.4)$ & & & $(56.3)$ & $(43.7)$ & $(53.6)$ & $(46.4)$ & & \\
\hline & Girls & 4 & 15 & 9 & 12 & 23 & 13 & 1.234 & 0.578 & 23 & 33 & 47 & 49 & 0.886 & 0.347 \\
\hline & & $(14.3)$ & $(53.6)$ & $(32.1)$ & $(25.0)$ & $(47.9)$ & $(27.1)$ & & & $(41.1)$ & $(58.9)$ & $(49.0)$ & $(51.0)$ & & \\
\hline \multirow[t]{4}{*}{ rs16917204 } & Boys & 58 & 82 & 34 & 36 & 51 & 24 & 0.181 & 0.913 & 198 & 150 & 123 & 99 & 0.123 & 0.726 \\
\hline & & (33.3) & $(47.1)$ & (19.5) & (32.4) & $(45.9)$ & (21.6) & & & (56.9) & (43.1) & $(55.4)$ & $(44.6)$ & & \\
\hline & Girls & 5 & 15 & 8 & 12 & 24 & 12 & 0.533 & 0.766 & 25 & 31 & 48 & 48 & 0.407 & 0.524 \\
\hline & & (17.9) & $(53.6)$ & (28.6) & $(25.0)$ & $(50.0)$ & $(25.0)$ & & & $(44.6)$ & $(55.4)$ & $(50.0)$ & $(50.0)$ & & \\
\hline
\end{tabular}

*comparisons were assessed using the Fisher's exact test. ADHD: attention-deficit/hyperactivity disorder, BDNF: brain-derived neurotrophic factor, 1: major allele (A for rs11030101, G for rs6265, G for rs16917204,), 2: minor allele

Table 3. Haplotype distribution of the three BDNF SNPs (rs11030101/rs6265/rs16917204)

\begin{tabular}{|c|c|c|c|c|c|c|c|c|}
\hline \multirow{3}{*}{$\begin{array}{c}\text { Haplotype } \\
\text { (rs11030101/ } \\
\text { rs6265/rs16917204) }\end{array}$} & \multicolumn{4}{|c|}{ Boys } & \multicolumn{4}{|c|}{ Girls } \\
\hline & \multicolumn{2}{|c|}{ Frequency } & \multirow{2}{*}{$\begin{array}{l}\text { Haplotype } \\
\text { specific p }\end{array}$} & \multirow{2}{*}{$\begin{array}{c}\text { Global } \\
\mathrm{p}\end{array}$} & \multicolumn{2}{|c|}{ Frequency } & \multirow{2}{*}{$\begin{array}{l}\text { Haplotype } \\
\text { specific p }\end{array}$} & \multirow{2}{*}{$\begin{array}{c}\text { Globa } \\
\mathrm{p}\end{array}$} \\
\hline & Cases & Controls & & & Cases & Controls & & \\
\hline A-C-A & 0.419 & 0.427 & 0.857 & 0.633 & 0.554 & 0.500 & 0.533 & 0.027 \\
\hline T-G-G & 0.310 & 0.301 & 0.817 & & 0.179 & 0.365 & 0.005 & \\
\hline A-G-G & 0.241 & 0.216 & 0.495 & & 0.232 & 0.125 & 0.048 & \\
\hline A-G-A & 0.014 & 0.037 & 0.108 & & 0.036 & 0.010 & 0.276 & \\
\hline T-C-G & 0.012 & 0.019 & 0.522 & & & & & \\
\hline
\end{tabular}

BDNF: brain-derived neurotrophic factor, SNP: single nucleotide polymorphism

Table 4. Transmission disequilibrium test results for BDNF rs6265 polymorphism in ADHD girls (20 trios)

\begin{tabular}{lllc}
\hline & \multicolumn{3}{c}{ Transmitted } \\
\cline { 3 - 4 } & & $\mathrm{A}$ & $\mathrm{G}$ \\
\hline Not transmitted & $\mathrm{A}$ & 10 & 5 \\
& $\mathrm{G}$ & 13 & 12 \\
\hline
\end{tabular}

Comparisons were assessed using the McNemar's $\chi^{2}$ test $\left(\chi^{2}=3.56\right.$, $\mathrm{df}=1, \mathrm{p}=0.059)$. ADHD: attention-deficit/hyperactivity disorder, BDNF: brain-derived neurotrophic factor

\section{DISCUSSION}

In our case-control and haplotype analyses, BDNF polymorphism was associated with ADHD in girls. The rs11030101 polymorphism was significantly related to commission errors, especially in girls. Thus, the results of this study suggest a gender-specific association of the BDNF gene with ADHD.

This gender-specific association of BDNF is in agreement with the well-known gender differences in the prevalence, course, and clinical features of ADHD. ${ }^{22}$ Recent studies suggest that many genes including BDNF, or the genetic variations within them, may act differently in males and females. ${ }^{23}$ Studies that have examined the sexually dimorphic effects of genes in ADHD have also been increasing. 24,25

Many of these gender effects may be the result of hormonal influences on gene expression and regulation or other non-genetic factors that are correlated with gender. In the case of BDNF, sex hormones may influence the activity and expression of BDNF-producing cortical neurons. In an animal model, estrogen was reported to regulate BDNF expression by directly interacting with an estrogen response element-like sequence ${ }^{26}$ and by indirectly modulating GABAergic interneurons. ${ }^{27} \mathrm{Un}$ fortunately, the mechanisms by which estrogen affects the developing human brain are ill defined. However, because estrogen levels differ between genders during the prepubertal period as well as during the prenatal period and after puberty, ${ }^{28}$ estrogen could contribute to the gender-specific modulation of BDNF gene in children with ADHD.

Moreover, our results are congruent with sexual dimorphism in brain structures involved in the neurobiology of $\mathrm{ADHD}$, par- 
Table 5. Interaction of BDNF rs11030101 genotype and gender on the results of the CPT, based on the MANOVA, in the subjects with ADHD

\begin{tabular}{|c|c|c|c|c|c|c|c|}
\hline & \multicolumn{2}{|c|}{ Boys } & \multicolumn{2}{|c|}{ Girls } & \multirow{2}{*}{$\begin{array}{c}\text { Gender } \\
\text { F,p }\end{array}$} & \multirow{2}{*}{$\begin{array}{c}\text { Genotype } \\
\text { F, p }\end{array}$} & \multirow{2}{*}{$\begin{array}{c}\text { Interactior } \\
\text { F,p }\end{array}$} \\
\hline & $\begin{array}{c}\text { AA } \\
\text { genotype }\end{array}$ & $\begin{array}{c}\mathrm{AT}+\mathrm{TT} \\
\text { genotype }\end{array}$ & $\begin{array}{c}\text { AA } \\
\text { genotype }\end{array}$ & $\begin{array}{c}\mathrm{AT}+\mathrm{TT} \\
\text { genotype }\end{array}$ & & & \\
\hline Omission errors & $61.4(17.3)$ & $60.4(18.9)$ & $69.5(20.4)$ & $67.9(18.1)$ & $3.44,0.066$ & $0.08,0.783$ & $0.00,0.963$ \\
\hline Commission errors & $64.0(28.6)$ & $63.5(24.2)$ & $76.2(38.9)$ & $54.2(19.7)$ & $0.06,0.811$ & $5.03,0.026$ & $4.68,0.032$ \\
\hline Reaction time & $53.4(19.2)$ & $49.6(18.2)$ & $53.6(23.0)$ & $62.8(20.6)$ & $3.56,0.061$ & $0.95,0.332$ & $3.41,0.067$ \\
\hline Reaction time variability & $62.2(14.4)$ & $60.8(14.1)$ & $66.9(13.2)$ & $60.4(13.7)$ & $0.39,0.534$ & $1.55,0.215$ & $0.69,0.407$ \\
\hline
\end{tabular}

ADHD: attention-deficit/hyperactivity disorder, BDNF: brain-derived neurotrophic factor, CPT: continuous performance test, MANOVA: multivariate analysis of variance

ticularly the prefrontal cortex. Brain development is known to differ between genders in typically developing children and adolescents, and this difference is more evident in the prefrontal cortex. ${ }^{29}$ Involvement of the prefrontal cortex is one of the bestreplicated findings with respect to brain regions associated with $\mathrm{ADHD},{ }^{30}$ and there is emerging evidence that the trajectories of early anomalous development of prefrontal cortex in ADHD is gender-specific. ${ }^{22}$ The BDNF gene has been reported to be associated with volume of prefrontal cortex both in animal ${ }^{31}$ and in human studies. ${ }^{32}$

The rs11030101 polymorphism is located within the BDNF intron and has no obvious functional consequences. However, in this study, strong linkage disequilibrium was observed with rs6265, also known as the Val66Met SNP, which causes an amino acid substitution of valine to methionine. Met-BDNF alters intracellular trafficking and activity-dependent secretion in neurosecretory cells and cortical neurons. ${ }^{33}$

Several limitations of this study should be noted. First, the sample size of this study was relatively small, and only $28 \mathrm{ADHD}$ and 48 control girls were included in the case-control analysis, which was small to avoid a sample bias. Second, there were significant differences between the ADHD and control groups with regard to gender and IQ. Although we performed the casecontrol and family-based analyses of boys and girls separately, the difference in IQ between the two groups could influence our results. Third, the association of BDNF and ADHD in the case-control analysis and MANOVA did not persist after correction for multiple testing. Fourth, the diagnosis of the ADHD subjects and controls was based on different diagnostic interview tools (K-SADS-PL-K or DISC-IV). However, good diagnostic validities have been established for both instruments, and the same rating scales (K-ARS and CBCL) were applied for diagnosis in both groups. Further studies with a greater number of subjects, especially girls, are required to validate our results.

Despite these caveats, the results of this study provide preliminary evidence for the sexually dimorphic effects of the BDNF gene among Korean patients with ADHD.

\section{Acknowledgments}

This study was supported by the Choi Shin Hae New Research Fund of Korean Neuropsychiatry Research Foundation in 2007.

\section{REFERENCES}

1. Barkley RA. ADHD in Adults. In: Barkley RA, editior. Attention-deficit hyperactivity disorder: A handbook for diagnosis and treatment. 3rd ed. New York: Guilford Press. 2006, p.248-296.

2. Banaschewski T, Becker K, Scherag S, Franke B, Coghill D. Molecular genetics of attention-deficit/hyperactivity disorder: an overview. Eur Child Adolesc Psychiatry 2010;19:237-257.

3. Huang EJ, Reichardt LF. Neurotrophins: roles in neuronal development and function. Annu Rev Neurosci 2001;24:677-736.

4. Hyman C, Hofer M, Barde YA, Juhasz M, Yancopoulos GD, Squinto SP, et al. BDNF is a neurotrophic factor for dopaminergic neurons of the substantia nigra. Nature 1991;350:230-232.

5. Traver S, Marien M, Martin E, Hirsch EC, Michel PP. The phenotypic differentiation of locus ceruleus noradrenergic neurons mediated by brainderived neurotrophic factor is enhanced by corticotropin releasing factor through the activation of a cAMP-dependent signaling pathway. Mol Pharmacol 2006;70:30-40.

6. Fumagalli F, Racagni G, Colombo E, Riva MA. BDNF gene expression is reduced in the frontal cortex of dopamine transporter knockout mice. Mol Psychiatry 2003;8:898-899.

7. Rios M, Fan G, Fekete C, Kelly J, Bates B, Kuehn R, et al. Conditional deletion of brain-derived neurotrophic factor in the postnatal brain leads to obesity and hyperactivity. Mol Endocrinol 2001;15:1748-1757.

8. Ribasés M, Hervás A, Ramos-Quiroga JA, Bosch R, Bielsa A, Gastaminza $\mathrm{X}$, et al. Association study of 10 genes encoding neurotrophic factors and their receptors in adult and child attention-deficit/hyperactivity disorder. Biol Psychiatry 2008;63:935-945.

9. Shim SH, Hwangbo Y, Kwon YJ, Jeong HY, Lee BH, Lee HJ, et al. Increased levels of plasma brain-derived neurotrophic factor (BDNF) in children with attention deficit-hyperactivity disorder (ADHD). Prog Neuropsychopharmacol Biol Psychiatry 2008;32:1824-1828.

10. Xu X, Mill J, Zhou K, Brookes K, Chen CK, Asherson P. Family-based association study between brain-derived neurotrophic factor gene polymorphisms and attention deficit hyperactivity disorder in UK and Taiwanese samples. Am J Med Genet B Neuropsychiatr Genet 2007;144: 83-86.

11. Lanktree M, Squassina A, Krinsky M, Strauss J, Jain U, Macciardi F, et al. Association study of brain-derived neurotrophic factor (BDNF) and LIN-7 homolog (LIN-7) genes with adult attention-deficit/hyperactivity disorder. Am J Med Genet B Neuropsychiatr Genet 2008;147B:945-951.

12. Schimmelmann BG, Friedel S, Dempfle A, Warnke A, Lesch KP, Walitza S, et al. No evidence for preferential transmission of common valine allele of the Val66Met polymorphism of the brain-derived neurotrophic factor gene (BDNF) in ADHD. J Neural Transm 2007;114:523-526.

13. Lee J, Laurin N, Crosbie J, Ickowicz A, Pathare T, Malone M, et al. Asso- 
ciation study of the brain-derived neurotropic factor (BDNF) gene in attention deficit hyperactivity disorder. Am J Med Genet B Neuropsychiatr Genet 2007;144B:976-981.

14. Gadow KD, Roohi J, DeVincent CJ, Kirsch S, Hatchwell E. Association of COMT (Val158Met) and BDNF (Val66Met) gene polymorphisms with anxiety, ADHD and tics in children with autism spectrum disorder. J Autism Dev Disord 2009;39:1542-1551.

15. So YK, Noh JS, Kim YS, Ko SG, Koh YJ. The reliability and validity of Korean parent and teacher ADHD Rating Scale. J Korean Neuropsychiatr Assoc 2002;41:283-289.

16. Oh KJ, Lee HR. Development of Korean version of Child Behavior Checklist (K-CBCL). Seoul: Korean Research Foundation Report; 1990.

17. Park KS, Yoon JR, Park HJ, Kwon KO. Korean Educational Developmental Institute-Wechsler Intelligence Scale for Children (KEDI-WISC). 2nd ed. Seoul: Korean Educational Development Institute; 2002.

18. Kim YS, Cheon KA, Kim BN, Chang SA, Yoo HJ, Kim JW, et al. The reliability and validity of Kiddie-Schedule for Affective Disorders and Schizophrenia-Present and Lifetime Version- Korean version (K-SADSPL-K). Yonsei Med J 2004;45:81-89.

19. Shaffer D, Fisher P, Lucas CP, Dulcan MK, Schwab-Stone ME. NIMH Diagnostic Interview Schedule for Children Version IV (NIMH DISCIV): description, differences from previous versions, and reliability of some common diagnoses. J Am Acad Child Adolesc Psychiatry 2000;39: 28-38.

20. Cho SC, Kim BN, Kim JW, Kim HW, Choi HJ, Jung SW, et al. The reliability and validity of Diagnostic Interview Schedule for Children Version IV-Korean Version (DISC-IV). J Korean Acad Child Adolesc Psychiatry 2007;18:138-144.

21. Shin MS, Cho SC, Chun SY, Hong KE. A study of the development and standardization of ADHD diagnostic system. J Child Adolesc Psychiatry 2000;11:91-99.

22. Mahone EM, Wodka EL. The neurobiological profile of girls with ADHD. Dev Disabil Res Rev 2008;14:276-284.

23. Weiss LA, Pan L, Abney M, Ober C. The sex-specific genetic architecture of quantitative traits in humans. Nat Genet 2006;38:218-222.
24. Guimarães AP, Zeni C, Polanczyk GV, Genro JP, Roman T, Rohde LA, et al. Serotonin genes and attention deficit/hyperactivity disorder in a Brazilian sample: preferential transmission of the HTR2A 452His allele to affected boys. Am J Med Genet B Neuropsychiatr Genet 2007;144B:69-73.

25. Biederman J, Kim JW, Doyle AE, Mick E, Fagerness J, Smoller JW, et al. Sexually dimorphic effects of four genes (COMT, SLC6A2, MAOA, SLC6A4) in genetic associations of ADHD: a preliminary study. Am J Med Genet B Neuropsychiatr Genet 2008;147B:1511-1518.

26. Solum DT, Handa RJ. Estrogen regulates the development of brain-derived neurotrophic factor mRNA and protein in the rat hippocampus. J Neurosci 2002;22:2650-2659.

27. Blurton-Jones M, Kuan PN, Tuszynski MH. Anatomical evidence for transsynaptic influences of estrogen on brain-derived neurotrophic factor expression. J Comp Neurol 2004;468:347-360.

28. Courant F, Aksglaede L, Antignac JP, Monteau F, Sorensen K, Andersson $\mathrm{AM}$, et al. Assessment of circulating sex steroid levels in prepubertal and pubertal boys and girls by a novel ultrasensitive gas chromatography-tandem mass spectrometry method. J Clin Endocrinol Metab 2010;95:82-92.

29. Lenroot RK, Gogtay N, Greenstein DK, Wells EM, Wallace GL, Clasen LS, et al. Sexual dimorphism of brain developmental trajectories during childhood and adolescence. Neuroimage 2007;36:1065-1073.

30. Seidman LJ, Valera EM, Makris N. Structural brain imaging of attentiondeficit/hyperactivity disorder. Biol Psychiatry 2005;57:1263-1272.

31. Baquet ZC, Gorski JA, Jones KR. Early striatal dendrite deficits followed by neuron loss with advanced age in the absence of anterograde cortical brain-derived neurotrophic factor. J Neurosci 2004;24:4250-4258.

32. Pezawas L, Verchinski BA, Mattay VS, Callicott JH, Kolachana BS, Straub $\mathrm{RE}$, et al. The brain-derived neurotrophic factor val66met polymorphism and variation in human cortical morphology. J Neurosci 2004;24:1009910102.

33. Chen ZY, Patel PD, Sant G, Meng CX, Teng KK, Hempstead BL, et al. Variant brain-derived neurotrophic factor (BDNF) (Met66) alters the intracellular trafficking and activity-dependent secretion of wild-type BDNF in neurosecretory cells and cortical neurons. J Neurosci 2004;24:4401-4411. 